\title{
Structural, functional, and evolutionary aspects of galectins in aquatic mollusks: From a sweet tooth to the Trojan horse
}

\author{
GR Vasta ${ }^{\ddagger 1}$, C Feng ${ }^{\ddagger}$, MA Bianchet ${ }^{\S}$, TR Bachvaroff ${ }^{\dagger}$, and S Tasumi ${ }^{\ddagger 2}$
}

${ }^{\ddagger}$ From the Department of Microbiology and Immunology, University of Maryland School of Medicine, and Institute of Marine and Environmental Technology, Columbus Center, 701 East Pratt Street, Baltimore, MD 21202, USA

${ }^{\S}$ From the Department of Neurology, and Department of Biophysics \& Biophysical Chemistry, The Johns Hopkins University School of Medicine, 725 North Wolfe Street, Baltimore, MD 21205, USA

${ }^{\dagger}$ From the University of Maryland Center for Environmental Science, and Institute of Marine and Environmental Technology, Columbus Center, 701 East Pratt Street, Baltimore, MD 21202, USA

${ }^{1}$ To whom correspondence should be addressed: Gerardo R. Vasta, Department of Microbiology and Immunology, University of Maryland School of Medicine, and Institute of Marine and Enviromental Technology, Columbus Center, 701 East Pratt Street, Baltimore, MD 21202, USA. Tel: (410) 234-8826; Fax: (410) 234-8896; E-mail: GVasta@ som.umaryland.edu

${ }^{2}$ Present address: Fisheries laboratory, The University of Tokyo, 2971-4 Bentenjima, Maisakacho, Nish-ku, Hamamatsu, Shizuoka 431-0214, JAPAN

Key words: galectin; phytoplankton; parasite; microbial recognition; glycan ligands

Running title: Galectins from aquatic mollusks 


\begin{abstract}
Galectins constitute a conserved and widely distributed lectin family characterized by their binding affinity for $\beta$-galactosides and a unique binding site sequence motif in the carbohydrate recognition domain (CRD). In spite of their structural conservation, galectins display a remarkable functional diversity, by participating in developmental processes, cell adhesion and motility, regulation of immune homeostasis, and recognition of glycans on the surface of viruses, bacteria and protozoan parasites. In contrast with mammals, and other vertebrate and invertebrate taxa, the identification and characterization of bona fide galectins in aquatic mollusks has been relatively recent. Most of the studies have focused on the identification and domain organization of galectin-like transcripts or proteins in diverse tissues and cell types, including hemocytes, and their expression upon environmental or infectious challenge. Lectins from the eastern oyster Crassostrea virginica, however, have been characterized in their molecular, structural and functional aspects and some notable features have become apparent in the galectin repertoire of aquatic mollusks. These including less diversified galectin repertoires and different domain organizations relative to those observed in vertebrates, carbohydrate specificity for blood group oligosaccharides, and up regulation of galectin expression by infectious challenge, a feature that supports their proposed role(s) in innate immune responses. Although galectins from some aquatic mollusks have been shown to recognize microbial pathogens and parasites and promote their phagocytosis, they can also selectively bind to phytoplankton components, suggesting that they also participate in uptake and intracellular digestion of microalgae. In addition, the experimental evidence suggests that the protozoan parasite Perkinsus marinus has co-evolved with the oyster host to be selectively recognized by the oyster hemocyte galectins over algal food or bacterial pathogens, thereby subverting the oyster's innate immune/feeding recognition mechanisms to gain entry into the host cells.
\end{abstract}




\section{Introduction}

Cell surface glycans contain complex information that when decoded by specific carbohydrate-binding proteins, can determine the nature and outcome of interactions between cells, or cells and the extracellular matrix (ECM). Among these proteins, the galectins [1-3] constitute a structurally conserved family of animal lectins defined by their affinity for $\beta$ galactosides, and a characteristic sequence motif in the carbohydrate recognition domain (CRD) $[4,5]$. Galectins are widely distributed in eukaryotic taxa, and their early emergence in evolution has been revealed by the presence of a protein with the galectin fold in the protistan parasite Toxoplasma gondii, and galectin-like proteins in the fungus Coprinopsis cinerea and in the sponge Geodia cydonium [6-8]. Galectins are present in the cytosol but also can be translocated into the nucleus, and in spite of lacking a typical secretion signal peptide [9], they can be secreted into the extracellular compartment by direct translocation across the plasma membrane [10-14]. Once secreted, galectins can bind to endogenous carbohydrate ligands on the cell surface or the ECM, namely glycoproteins or other glycoconjugates that display non-reducing terminal ß-galactosides or polylactosamine chains [15]. These include laminin and fibronectin, mucins, lysosome-associated membrane proteins, and numerous cell surface signaling glycans, such as integrins and Muc1 [16-19]. In addition, some galectins can also recognize exogenous ligands, such as glycans on the surface of microbial pathogens [20-27].

\section{Structural and functional features of the galectin family}

Based on their domain organization, mammalian galectins have been classified in three types: "proto", "chimera", and "tandem-repeat" (Fig. 1A) [9]. Proto type galectins contain one CRD per subunit, and are usually homodimers of non-covalently-linked subunits. The chimera type galectins have a $\mathrm{C}$-terminal similar to the proto type and a non-CRD N-terminal domain rich in proline and glycine. Tandem-repeat galectins, in which two CRDs are joined by a linker peptide, are monomeric. Proto- and tandem-repeat types comprise several distinct galectin subtypes, which have been numbered following the order of their discovery [28], and so far, 15 have been described in mammals $[9,15,28,29]$. Gal1, 2, 5, 7, 10, 11, 13, 14, and 15 are examples of the proto type galectins, of which Gal5 is a monomer, whereas all others are 
homodimers. Gal3 is the only chimera type galectin, whereas Gal4, 6, 8, 9, and 12 are tandemrepeat type galectins. Among ectothermic vertebrates such as teleost fish and amphibians, the three major galectins types identified in mammals are mostly present, although the subtypes are less diversified [4, 30-33].

In contrast, invertebrates and earlier taxa such as sponges, fungi, and protista express galectins with domain organizations that in most cases do not fit within any of the three major galectin types described in mammals. Furthermore, some galectin-like proteins such as the mammalian lens crystallin protein GRIFIN (galectin related inter-fiber protein) and the galectinrelated protein GRP (previously HSPC159; hematopoietic stem cell precursor) lack carbohydrate-binding activity $[34,35]$. As the zebrafish GRIFIN orthologue is endowed with the typical carbohydrate binding activity of galectins, it has been proposed that the mammalian GRIFIN is a product of evolutionary co-option [35].

Although relatively conserved from a structural standpoint, galectins display a surprising functional diversification. The biological roles of selected members of the galectin family have been elucidated only in the past few years [36]. The available information is fragmentary, however, and among the numerous subtypes expressed in mammals, the roles of only a few galectins such as Gal1, Gal3, and Gal9, have been elucidated to a considerable extent [37].

1. Functions of galectins in early development: Since their discovery, galectins have been proposed to participate in embryogenesis and development. This has been based on their binding to endogenous "self" carbohydrate moieties, such as polylactosamine-containing glycans, abundant at the cell surface and the ECM. Chicken galectins have been proposed to participate in myoblast fusion, whereas murine Gal1 and Gal3 would have roles in notochord development, somitogenesis, and development of muscle tissue and central nervous system [11, $28,32,38,39]$. In recent years, the roles of galectins in cancer metastasis and angiogenesis have been investigated in detail, with promising potential for therapeutic intervention [40-42]. In addition, the availability of non-mammalian genetically tractable model organisms endowed with a less diversified galectin repertoire such as Drosophila melanogaster, Caenorhabditis elegans, and zebrafish (Danio rerio) have become attractive alternatives for investigating functional aspects of galectins from an evolutionary standpoint [43].

2. Functions of galectins in innate and adaptive immunity: By binding to endogenous carbohydrate ligands, mammalian galectins such as Gal1, Gal3 and Gal9, mediate diverse 
biological processes that are key to regulation of innate and adaptive immune homeostasis [4449]. For example Gal1 participates in acute and allergic inflammation [29], and influences the ability of macrophages to control intracellular infections either by inhibiting microbicidal activity or inducing host-cell apoptosis [50]. With regards to adaptive immune functions, galectins and their ligands have been proposed as regulators of immune cell homeostasis [50]. For example Gal1 inhibits proliferation of mitogen-activated T cells, and reduces clonal expansion of antigen-primed CD8+ T cells and human leukemia $\mathrm{T}$ cells in a carbohydratedependent manner and induces apoptosis of T cells during development in the thymus [46].

Insight into the multiple roles of galectins in both innate and adaptive immune functions has further expanded recently by discovery of their ability to directly recognize microbial pathogens, a property shared with other lectin types, such as C- and F-lectins, ficolins, and pentraxins [27]. The roles of lectins in recognition of microbial glycans are particularly critical in invertebrates, since these organisms lack immunoglobulins and rely solely in innate immune mechanisms for recognition of potential microbial pathogens [5]. This seems to be the case even in vertebrate taxa, since it has been reported that susceptibility/resistance to several infectious diseases in humans are determined by the presence of certain lectin alleles [51]. Whether galectin-mediated recognition is an effective defense mechanism with a clear benefit for the host is not entirely clear, except for a few examples discussed above [52, 53]. In some cases, however, recognition of the microbe by the vector or host galectins promote its adhesion, host cell entry, or infection persistence, in addition to modulating the host's immune responses [27, 54].

\section{Galectins in aquatic mollusks}

In contrast with other animal taxa, the identification and characterization of bona fide galectins in aquatic mollusks has been relatively recent [37]. The first species to be rigorously investigated in this regard has been the eastern oyster Crassostrea virginica [55-60]. Although the presence of multiple galactosyl binding lectins had been already reported in this species [55, 56], their lectin family identity had remained unresolved. Further studies revealed that some of the sugars recognized by the oyster lectins coincided with the sugars present on the surface of the Perkinsus marinus trophozoites and a galectin ( $\mathrm{CvGal}$ in the initial publication [57] and currently 
CvGal1 [58]) of unique domain organization, carbohydrate specificity, and biological role was identified as a receptor for the parasite on the hemocyte surface [57]. Further studies were aimed at the structural and functional characterization of $\mathrm{CvGal} 1$ at the gene, transcript, and protein levels [58], and included the glycomic analysis of its natural carbohydrate ligands [59]. The initial sequence analysis of CvGal1 revealed the presence of four canonical galectin CRDs [57], a domain organization that did not fit any of the galectin types (proto, chimera or tandem-repeat) that had been described at the time $[9,28,29]$. During the following year, galectin-like sequences were reported in the close relative, the Pacific oyster Crassostrea gigas [61] and in the freshwater snail Biomphalaria glabrata [62]. Since then, galectins have been identified in an increasing number of aquatic mollusk species, including both bivalves and gastropods (Table I). Most of these studies consisted in the identification and domain organization of galectin-like molecular species (mostly transcripts) in diverse tissues and cell types, including hemocytes, and their expression upon environmental or infectious challenge [62-71]. Some notable features have become apparent in the galectin repertoire of aquatic mollusks, that differ from those described for vertebrate species. First of all, the galectin repertoires in mollusk species are less diversified, as only up to four distinct galectins have been identified in most species (most commonly one or two), in contrast with the mammalian repertoires that comprise up to over a dozen distinct galectins. Further, galectins from aquatic mollusks display a domain organization which is different from those from vertebrates. Finally, in most mollusks examined to date, the expression of galectins is upregulated by infectious challenge [57, 58, 62-71], an observation that supports their proposed role(s) in innate immune responses [57].

1. Domain organization and gene structure: In contrast with the three galectin types identified in vertebrates, proto, chimera, and tandem repeat types, galectins identified so far in mollusks can be classified in two major types based on the number of CRDs: the 2-CRD and the 4-CRD types (Fig. 1.B). Exceptions to these two major groups are the single CRD galectin described in C. gigas [61], and the most recently described transcript of a chimeric galectinrelated protein (GREP) in B. glabrata [72]. It should be noted that the designation as "tandem galectins" of the 2-CRD galectins from aquatic mollusks reported in several publications is avoided in this article, as there is no rigorous evidence that these galectins are orthologues of the bona fide tandem-repeat type galectins from vertebrates. Actually, a preliminary phylogenetic analysis suggested the contrary [57]. 
The 4-CRD galectins are proteins of approximately 560 amino acid-long polypeptides, of approximate MW of $64 \mathrm{kDa}$ in which four similar but not identical CRDs are separated by short linker peptides ranging from 8 to 17 amino acid residues [57, 60]. The 2-CRD galectins consist of 280 to 300 amino acid-long polypeptides, of approximate MW of $32 \mathrm{kDa}$ in which two similar but not identical CRDs are separated by a 10-15 amino acid-long linker peptide [62]. The only galectin carrying a single CRD that has been identified so far in a bivalve species was described in C. gigas as a transcript that encodes a protein of 140 amino acids [61]. It should be noted that the CRD sequence included in this transcript (EKC40502) appears to be the same as one of the CRD sequences in CgGal9 (Accession \#EKC40501), a 2-CRD galectin sequence also identified in $C$. gigas. Among the aquatic gastropods, a full-length transcript recently identified in the freshwater snail B. glabrata, encodes a unique mosaic polypeptide (galectin-related protein; GREP) consisting of two immunoglobulin superfamily domains (IgSF1 and IgSF2) upstream of a C-terminal galectin-like domain [72] (Fig 1.B). The galectin-like domain GREP sequence is considerably divergent from other galectins reported so far, and in spite of the conservation of amino acid residues that are key for ligand binding and dimerization in vertebrate galectins [72], a preliminary attempt for modeling this domain on a vertebrate galectin template carried out for the present study, failed to reveal the typical galectin carbohydrate-binding site, suggesting that it may lack carbohydrate binding activity.

The only gene structure elucidated for a galectin from an aquatic mollusk species is that of the gene encoding for the 4-CRD galectin CvGal1 from $C$. virginica [57]. The organization of the $C v G a l 1$ gene confirmed the presence of four tandemly arrayed CRDs in the CvGall protein [57]. The CvGal1 gene, which is present as a single copy, comprises 12 exons of lengths ranging from 86 to 328 bp separated by 11 introns of variable lengths, none of which is present within the regions encoding the individual CRDs. In the $C v G a l 1$ gene, the nearest predicted promoter region is located from 124 to $75 \mathrm{bp}$ and the predicted transcription initiation site at $84 \mathrm{bp}$. The position of the first intron of $\mathrm{CvGal1}$, between 8th and 9th amino acid residues, is identical with that of Lec-6, a 16-kDa galectin from C. elegans [73, 74], and different from the mammalian proto type galectins, where it is located between 2 nd and 3rd, or 3rd and 4th amino acid residues [9]. Furthermore, the exon number and organization in $C v G a l l$ is also clearly different from the proto type galectins from ectothermic vertebrates such as zebrafish and those from mammals since these comprise four exons, of which exon 3 houses all the amino acid residues that bind the 
carbohydrate ligand $[31,75,76]$. Unfortunately, no other gene structures for galectins from aquatic mollusk species, neither bivalves nor gastropods, have been reported so far that would enable a detailed comparison of their organization with the CvGal1 gene.

2. Carbohydrate specificity: Although galectins from vertebrates have been defined by their conserved recognition of non-reducing $\beta$-galactosides by the primary binding pocket, the detailed study of their specificity for oligosaccharides by the extended binding site has revealed that the different galectin family members display significant differences in their recognition properties. Furthermore, the N-terminal and C-terminal CRDs of the tandem-repeat type galectins, exhibit similar but yet distinct specificites for oligosaccharides [36].

Most of the studies on galectins from aquatic mollusks have been focused on the domain organization revealed by the sequence of their transcripts and the modulation of their expression by various challenges [57, 58, 62-71]. Although some studies have revealed their binding to microbes or microbial products $[62,65,66]$, virtually no biochemical analyses have been carried out other than those conducted on galectins from the eastern oyster $C$. virginica [57]. Early studies in $C$. virginica implementing serological and biochemical approaches by agglutination of human (A, B and $\mathrm{O}$ ) and animal erythrocytes and agglutination-inhibition revealed the presence of multiple soluble and cell membrane-associated lectins in tissues, hemocytes, and biological fluids with binding preferences for galactose and $\mathrm{N}$-acetylgalactosamine $[55,56]$. The identification of galectins among the various members of the oyster's lectin repertoire and the characterization of their specificity by solid phase binding and binding-inhibition assays, together with the detailed analysis of specificity by a glycan array technology (Fig 2) revealed their specificity for ABH blood group oligosaccharides [57, 58, 60]. Furthermore, in contrast with most galectins analyzed so far, the initial studies on CvGl1 indicated that it displayed stronger binding to galactosamine and $\mathrm{N}$-acetylgalactosamine relative to D-galactose [57]. Results of the binding of CvGall to a glycan array indicated that it preferentially recognizes type 2 blood group A oligosaccharides (Fig 2) [57]. The application of biophysical methods such as surface plasmon resonance (SPR) enabled the measurement of the affinities of the galectins of interest for their ligands identified from the glycan arrays, and have been consistent with the recognition specificity or binding preferences expected from the structural analysis of the docking models and the molecular interactions identified [58]. The specificity of the binding of CvGall to cell surfaces, including both the oyster hemocytes and the P. marinus trophozoites 
was assessed by the use of solid phase assays and FACS, together with the use of ABH-specific monoclonal antibodies and specific glycosidase treatments [58], and confirmed the glycan array results. A proteomic analysis of the CvGal1 "self" ligands isolated from the oyster hemocyte surface by mass spectrometry revealed the presence of multiple peptides that mostly matched $\beta$ integrin and dominin. Finally, a rigorous glycomic study that combined HPLC fractionation, exoglycosidase digestion and fragmentation, and mass spectrometry analysis of the CvGal1 ligands in oyster plasma and the hemocyte glycome revealed interesting features [59]. The oyster plasma contains $\mathrm{N}$-glycans comprising simple hybrid structures with terminal $\beta 1,3$-linked galactose, that in some cases can be methylated and core $\alpha 1,6$-fucosylated [59]. Hemocytes express a more diverse glycan repertoire that comprises core-difucosylated paucimannosidic forms as well as bi- and triantennary glycans, including structures carrying sulfated and methylated variants of the blood group A epitope [59]. The presence of ABH blood group oligosaccharides in glycoproteins present in plasma and associated with the hemocyte surfaces, such as dominin, provides the rationale for the observed binding of CvGall to the hemocyte surface $[58,59]$.

3. Structural aspects: Although no crystal structures of galectins from aquatic mollusks have been resolved so far, the substantial conservation of the galectin structural fold, the amino acid residues in the CRD that interact with the carbohydrate ligands, and those residues that are responsible for establishing the architecture of the binding site has enabled the development of accurate homology models using crystal structures as templates [58]. In addition, availability of glycan arrays for the elucidation of the detailed carbohydrate specificity of the proteins and the recent development and optimization of bioinformatic tools for ligand docking experiments has enabled the visualization of the the 3-D structure of the binding site and the multiple direct or water-mediated interactions of the amino acid residues in the CRD with the oligosaccharide(s) recognized $[58,60]$. Furthermore, the modeling and docking structural studies, combined with the glycan array analyses indicated not only that the 4-CRD galectins from $C$. virginica exhibit a unique specificity for $\mathrm{ABH}$ blood group oligosaccharides, but also that the 4 CRDs exhibit differences in their binding properties (Fig 3), suggesting that these proteins are endowed of uniquely broad recognition capabilities [58].

The model of CvGal1 (Fig 3.A) provided the structural basis for its preference for nonreducing terminal GalNAc and blood group oligosaccharides as revealed by the glycan array 
analysis, and the main feature common to the four CRDs (A, B, C, and D) is the significantly shorter loop 4 as compared to that present in galectins from vertebrates. Docking experiments for the binding of type 2 blood group A oligosaccharide (A2) to the first CRD (N-CRD) of CvGal1 was used as representative of the recognition of A and B blood group antigens by all four CRDs of CvGall. The $2^{\prime}$-fucosyl moiety of the tetrasaccharide, which is a feature common to both the A and B blood group oligosaccharides, is accommodated in the space generated by the shortening of loop 4 with its 6-methyl group positioned on top of the arginine residue that coordinates the equatorial $\mathrm{OH}$ group of the core galactoside's second moiety. Although no direct interaction(s) of a protein polar group with fucose hydroxyls were identified, some amino acid residues (which are different in the A, B, C and D CRDs) could potentially establish watermediated bridges between the protein and the fucose 4-OH group. The $\alpha(1-3)$-linked GalNAc or Gal moieties of the A and B blood group tetrasaccharides, respectively, are recognized by the 5NH of the conserved tryptophan (Trp77 in the CvGal1 N-CRD), and a hydrophobic pocket at the external side of the strand $\beta 3$ (amino acids 30 to 38 ) recognizes the methyl of the 2-NAc group of $\alpha 3$-linked GalNAc of A1/2 antigens. The $\alpha(1,3)$ anomeric linkage of GalNAc to the subterminal galactose also contributes to the specificity of CvGall for blood group A oligosaccharides, as the 6-OH of the $\alpha(1,3)$-linked galactose forms an $\mathrm{H}$-bond with the 5-NH group of the binding site tryptophan in CvGal1 [58]. As shown in (Fig 3.B), the CRDs B, C and $\mathrm{D}$ are similar but not identical in structure to the CRD A used as the representative in the descriptions above, and their ligand preferences are different as well.

A comparison of the CvGal1 CRD from the bivalve $C$. virginica (Fig 4.A) with galectins from the taxonomically distant gastropods Reishia clavigera and B. glabrata revealed notable similarities, but also substantial differences (Fig 4.C, D). Consistently with the conserved binding specificity of the galectin family members, the galectins from $R$. clavigera (AET43927) and B. glabrata (ABQ09359) (Table I) also exhibit CRDs that carry the canonical residues that bind to the non-reducing terminal $\beta$-galactoside. Furthermore, the $R$. clavigera galectin and the $\mathrm{N}-\mathrm{CRD}$ of BgGal display the short loop 4 observed in the CvGal1 CRDs, suggesting that they can also bind to the H2 and B2 blood group oligosaccharides. However, the presence of an Arg in the most internal $\beta$-strand (B11) of the binding site, could sterically hinder the binding to A2. In contrast, the additional Arg could enhance recognition of the $2^{\prime}-\alpha$-fucosyl moiety, or any sulfate or phosphate groups substituting in the $\alpha$-linked galactose, while it could also clash with 
the $\mathrm{N}$-acetyl group of GalNAc, preventing binding to blood group A oligosaccharides. Like for the oyster galectins, however, homology modeling and docking of the oligosaccharide ligands of BgGal revealed that the $\mathrm{N}$ - and C-CRDs are quite different in both structure and specificity. This is mainly due to the relatively longer loop 4 in the C-CRD of $\mathrm{BgGal}$, which is similar in length to the same loop in galectins from vertebrates, such as the toad Bufo arenarum [77] (Fig 4. B). Therefore, the $\mathrm{BgGal}$ C-CRD would only recognize $\mathrm{H} 2$ and linear B blood group oligosaccharides, with the additional contribution of an aromatic residue that improves the recognition of the $\beta$-galactose (Fig 4.C).

4. Phylogenetic analysis: The phylogenic relationships among the available sequences of galectins from both aquatic bivalves and gastropods listed in Table I were analyzed on the basis to two different sequence alignment approaches. The first compared the full-length sequences of galectins from bivalves and gastropods that were included in a selected galectin type, in this case the 2-CRD galectins. The second alignment approach was implemented with the sequences of the individual CRDs of the two major galectin types, the 2-CRD and 4-CRD types, in both bivalves and gastropods, with the CRDs designated from $\mathrm{N}$ - to $\mathrm{C}$-terminus as $\mathrm{A}, \mathrm{B}, \mathrm{C}$, and $\mathrm{D}$. Maximum likelhood phylogenies of the full-length sequences or the individual CRDs were constructed with a shrimp galectin as the outgroup, with bootstrap support (100 replicates) shown above the branches when over $50 \%$.

The phylogenetic analysis of the full-length sequences of the 2-CRD galectins revealed that the galectins from bivalves and gastropods formed two well-supported monophyletic clades with $95 \%$ bootstrap support, suggesting that the 2-CRD galectins diverged consistently with the evolution of the bivalve and gastropod taxa (Fig 5.A). When the individual CRDs of the 2-CRD and 4-CRD galectins from bivalves and gastropods were analyzed, the results were surprising in that the phylogeny clearly shows a distinct, well-supported (98\% bootstrap) difference between the 2-CRD and the 4-CRD galectins (Fig 5.B). In addition, each individual domain in both the 2- and 4-CRD galectin types formed a monophyletic group, albeit with weaker bootstrap support for the 2-CRD proteins. In the six clades corresponding to individual domains the bivalves and gastropods formed two distinct clades only once, the gastropods were embedded within the bivalves four times, and the bivalves within the gastropods only once. The simplest interpretation of the phylogeny is that the 2-CRD and 4-CRD galectins were already present in the most recent common ancestor of both bivalves and gastropods, and that the individual CRDs in both the 2- 
CRD and 4-CRD galectins have been maintained in the same arrangement/sequence without domain shuffling since the divergence of these two major clades. This remarkable structural conservation of the biologically active carbohydrate-binding domains in the evolution of the mollusk taxa supports the key roles of galectins in essential biological functions related to Bgalactoside recognition. In addition, there were two distinct 4-CRD galectins within the two representatives of the genus Crassostrea (C. virginica and $C$. gigas), and it is noteworthy that in each of the individual CRD clades the Gal2 sequence was on a longer branch than the Gal1 sequence. This suggests that even within closely related species like $C$. virginica and $C$. gigas, the Gal1 and Gal2 genes which belong to the same 4-CRD galectin type, would evolve at different rates, based on the branch length in the phylogeny.

5. Tissue distribution: It is generally recognized that the localization of any given galectin in particular tissues and fluids of the organism under study can provide valuable clues about the galectin's biological role(s). Therefore, the spatial distribution of galectin transcripts and mature proteins in selected tissues and cell types of aquatic mollusks has recently become a matter of great interest. At present time, however, documented information about the potential tissue-specific expression and localization of the galectins is only available for a limited number of aquatic mollusk species, including Crassostrea virginica, Biomphalaria glabrata, Solen grandis, Argopecten irradians, Ruditapes philippinarum and Pinctada fucata [57, 58, 60, 62-68]. The experimental approaches implemented to examine the spatial distribution of galectin transcripts in tissues and selected cell types such as hemocytes, have consisted of RT-PCR with primers based on galectin sequences obtained by cloning in the species of interest, or from public databases. The localization of the mature proteins has been assessed by Western blot, using specific anti-galectin antibodies generated against the particular galectin of interest, and in some examples, antibodies that have been demonstrated as cross-reactive with the galectin under investigation.

In most aquatic mollusks species examined, the expression and tissue distribution of the galectins identified appears to be quite ubiquitous, particularly in tissues that include mucosal surfaces exposed to the external environment, such as gills, gut, and mantle, with the almost invariable presence of galectin transcripts and protein in hemocytes [57, 58, 60, 62-68]. In some examples, the highest galectin expression was measured in these cells [57]. This is relevant to the potential role(s) of galectins in the immune responses, as in aquatic mollusks the hemocytes are 
abundant in all aforementioned tissues, which represent the interface of the internal milieu with the external environment. Because in none of the reports these tissues examined have been cleared from resident or circulating hemocytes, it is possible that these cells significantly contribute to the signals detected either by PCR amplification or by western blot [57].

6. Functional aspects: It is well established that lectins from various families such as Ctype and F-type lectins play key roles both in self/non-self recognition and as effector factors in innate immunity [37]. Although galectins were initially described as mediating key functions in early development $[11,28,38,39]$, in the past few years ample evidence has accumulated to support their roles as regulators of immune homeostasis [50], and more recently, in direct recognition of viruses, bacteria and eukaryotic parasites [27]. Thus, the expression and localization of galectins in hemocytes, cells that patrol the mucosal interfase of aquatic mollusks with their external environment, and which is subject to continued microbial challenges, has generated interest in their potential role(s) in immune recognition and defense [57].

\section{a. Regulation of expression and secretion of galectins by immune challenge: It} is widely recognized that in vertebrates the expression of innate and adaptive immune recognition/effector factors such as pentraxins and immunoglubulins is upregulated by microbial challenge, and their secretion by the cells responsible is enhanced [78]. Similarly, the expression and secretion of C-type lectins and antimicrobial peptides by hemocytes has been amply demonstrated in varios invertebrate systems [79]. In aquatic mollusks, several studies have examined by RT-PCR or Western blot the regulation of expression and secretion of galectins by exposing the live animals or their hemocytes to infectious challenge, by either bacteria or bacterial products, or protozoan parasites. For most species investigated, the exposure to immune challenge increases galectin expression and secretion [57, 58, 60, 62-68]. For example, galectinlike transcripts were upregulated by immune challenge in gills and hemocytes of the Pacific oyster $C$. gigas $[80,81]$. An exception appears to be the single CRD galectin $\mathrm{CgGal}$ from $C$. gigas, in which injections of Vibrio tubiashii into the adductor muscle, failed to upregulate its expression [61]. In the eastern oyster, the expression of galectin CvGal1 is upregulated in vivo and in vitro by exposure of the oysters or the hemocytes to a $P$. marinus challenge [57]. The contact of circulating hemocytes with a foreign surface, followed by hemocyte attachment and spreading, leads to the release of CvGal1 to the extracellular environment [57]. Upon release, the galectins can bind to the hemocyte surface glycans such as the $\beta$-integrins and dominin described 
above, or remain soluble in the surrounding fluid, plasma or mucus [57]. The hemocyte-bound and soluble CvGal1 can bind to the microalgal cells, potentially pathogenic bacteria, or parasites such as $P$. marinus, and cross-link them to the hemocyte cell surface [57].

\section{b. "The sweet tooth": Galectins can recognize carbohydrate ligands on cell}

surfaces of both microalgae and microbial pathogens: Phagocytic hemocytes from invertebrates can recognize and internalize both biotic and abiotic particles via nonspecific or specific mechanisms. Surface properties of the particle such as wettability, hydrophobicity, or electric charge, have been proposed to determine nonspecific recognition leading to phagocytosis or encapsulation by invertebrate hemocytes [53]. However, a variety of pattern recognition receptors including peptidoglycan recognition proteins [82-84], integrins [85], and lectins [86, 87] have been shown to mediate specific recognition leading to phagocytosis. Most cells are decorated with a complex glycocalyx that encodes abundant structural information, which is decoded by carbohydrate-binding proteins such as lectins. Among the various lectin families that can function as pattern recognition receptors (PRRs), such as C- and F-type lectins and pentraxins, galectins are endowed with effective recognition properties for a variety of viruses, bacteria and eukaryotic parasites [27]. Galectins from aquatic mollusks are no exception, and their recognition of potentially pathogenic bacteria such as Vibrio spp and parasites such as Perkinsus spp and Schistosoma spp has been reported for several species of bivalves and gastropods $[57,62,65,66]$. In addition, microalgal species commonly found in estuarine phytoplankton are also selectively recognized by the eastern oyster galectin CvGal1 [57].

In some examples, the galectins can not only bind but also agglutinate the recognized bacteria or protozoan parasites [57, 62, 65, 66]. In this regard, the presence of two or four CRDs with similar but yet distinct binding properties in a single galectin subunit, endows these galectins with a broad recognition capacity that perhaps compensates for the less diversified galectin repertoire as compared to those from vertebrates [27]. Furthermore, as galectin-ligand interactions are relatively weak compared with other immune recognition molecules, high avidity for the target is achieved by the multiple CRDs simultaneously interacting with ligand. Therefore, the 4-CRD galectins (and to a lesser extent the 2-CRD galectins) from aquatic mollusk species may have the potential for cooperative, high avidity binding as well as crosslinking of the recognized microbial glycans with the hemocyte surface, leading to their opsonization and phagocytosis $[57,88,89]$. Further, the binding of the multiple CRD galectins to 
glycans on the hemocyte surface would facilitate glycan crosslinking and lattice formation, which trigger signaling pathways leading to cell activation $[15,90]$.

Based on the presence of conserved amino acid residues that in the prototype galectins from vertebrates form the dimer interphase, it has been proposed that the C-terminal galectin-like domain of the chimeric GREP, that is joined to two IGSF domains, has the capacity to form dimers or multimers and participate in immune recognition [72]. However, no evidence of binding to carbohydrate ligands has been reported [72].

The 4-CRD galectin CvGal1 from the eastern oyster $C$. virginica recognizes and promotes phagocytosis of Perkinsus spp as shown by the significant reduction in phagocytosis that takes place upon pre-treatment of the hemocytes with an anti-CvGal1 galectin. The selective recognition of both Gram - and Gram + bacteria, some potentially pathogenic species including Aeromonas spp, Carnobacterium spp, Streptococcus spp, Bacilus spp, and Vibrio spp that may be internalized during filter-feeding of phytoplankton, suggest that these species may be opsonized by the oyster CvGal1, phagocytosed, killed by the hemocyte respiratory burst, and digested in the phagosome compartment by the lysosomal enzymes [57]. Thus, CvGal1 would function as a key component of the innate immune defense [27, 57]. The protective role of mammalian galectins against viral and bacterial infection has been reported in recent years [9193]. The oyster galectin CvGall also selectively and specifically recognizes microalgal species such as Tetraselmis spp, an abundant phytoplankton component in the oyster's diet internalized by filter-feeding, suggesting that $\mathrm{CvGal1}$ is also involved in selective phagocytosis and intracellular digestion of the microalgal food [27, 57] (Fig 6.A). A similar role was later reported for C-type lectins present in mucus in the same oyster species [94]

\section{c. "The Trojan horse": Some parasites and microbial pathogens can subvert}

immune/feeding functions mediated by galectins: As mentioned above, the oyster galectin

CvGal1 is secreted by the hemocytes upon recogition of a foreign surface or particle, binds to the hemocyte surface, and the remaining protein remains as soluble protein in extracellular space [57]. Therefore, it can function either as a cell surface receptor or as an opsonin for the recognition and phagocytosis of phytoplankton and bacteria. The equally selective and strong recognition of $P$. marinus trophozoites and the specific inhibition of its phagocytosis by an antiCvGal1 antibody revealed that $P$. marinus trophozoites can outcompete the recognition of microalgal food or bacteria by CvGal1 to be preferentially internalized by the phagocytic 
hemocytes [27, 57] (Fig 6.B). Thus, if during filter-feeding a few P. marinus trophozoites are ingested in a pool of phytoplankton, ie. Tetraselmis sp and Isochrysis sp., CvGall can provide a selective advantage for the preferential phagocytosis of the parasite relative to the algal food by the gill, mantle, palp, or gut hemocytes [27, 57]. Once internalized, the parasite would inhibit the hemocyte's typical respiratory burst by a powerful anti-oxidative machinery [95-100], proliferate and lyse the carrier hemocytes [101], and the released trophozoites ingested by other circulating or attached hemocytes that would become activated upon recognition of the parasite surface and the binding of released CvGal1 [57]. Therefore, the experimental evidence suggests that $P$. marinus has co-evolved with the oyster host to adapt the trophozoite's glycocalyx to be selectively recognized by the oyster hemocyte CvGall over algal food or bacterial pathogens, thereby subverting the oyster's innate immune recognition mechanism to gain entry into the host cells [27].

The subversion of galectin functions by viruses, bacteria, and other eukaryotic parasites recently reported has consistently supported the proposed oyster/Perkinsus model. For example, the 2-CRD galectin (BgGal) identified in the freshwater snail B. glabrata, the intermediate host of Schistosoma mansoni, was proposed to mediate snail-parasite interactions [62]. Similarly, the Leishmania major procyclic promastigotes that are ingested with the blood meal by the sandfly Phlebotomus papatasi attach to the midgut via a 2-CRD galectin (PpGalec) that is only expressed by epithelial midgut cells and is upregulated in bloodfeeding females [102]. As the parasites mature in the midgut into metacyclic promastigotes their polygalactose epitopes recognized by PpGalec are masked with arabinose, and the free-swimming and infective metacyclic promastigotes are released from the midgut for transmission from the sandfly to the mammalian host [102]. Thus, the sandfly midgut PpGalec is key to parasite survival and maturation during the promastigote stage [102]. In HIV-1-infected individuals, galectin 1, which is abundant in organs that represent major viral reservoirs, such as the thymus and lymph nodes, promotes further T cell infection by facilitating HIV-1 attachment to the host cell surface glycans [103]. Furthermore, galectin-1 also mediates the attachment of Trichomonas vaginalis, an obligate extracellular parasite, to the cervix epithelium $[104,105]$. These observations are in sharp contrast with the protective role of the same galectin-1 during infections by influenza A virus [93] and Dengue virus [92]. Therefore, these examples further support the notion that although galectins may participate as PRRs in innate immune recognition by both invertebrates 
and vertebrates, including man, some viral and bacterial pathogens and parasites have co-evolved with their host to subvert the defensive role of galectins to gain entry into the host internal milieu [27].

\section{Conclusions and future directions}

From the above it becomes clear that although significant progress has been accomplished in recent years about the molecular, structural, functional, and evolutionary aspects of galectins in aquatic mollusk species, wide gaps in our knowledge that warrant further investigation still exist. For example, although galectins are considered critical mediators in embryogenesis and early development processes in vertebrates, including mammals, no studies on the potential roles of galectins in development have been reported for mollusk species. Furthermore, the structural and functional information is still very limited, in particular on the detailed mechanisms of recognition of microbial glycans and the downstream processes that take place as part on the immune responses mediated by galectins for aquatic mollusks. As the consumer demand for shellfish has continued to increase worldwide, so has the rate of infectious disease in the aquaculture industry settings for marine and estuarine bivalves. Furthermore, as intermediate hosts of biomedically relevant parasites, aquatic gastropods such as B. glabrata are of great relevance in multiple regions of the world. Therefore, there is an urgent need to address mechanistic questions concerning the galectin-mediated immune responses of aquatic mollusks to microbial pathogens and parasites, and it is expected that increased attention will be given to this area of research.

\section{Acknowledgments}

The authors' research reviewed herein was supported by grants IOS-0822257 and IOS1063729 from the National Science Foundation, and grant 5R01 GM070589-06 from the National Institutes of Health to GRV. 
Table I. Galectins identified in aquatic mollusk species

\section{Bivalvia (Bivalves)}

Crassostrea virginica

(Eastern oyster)

$\begin{array}{llll}\text { CvGal1 } & 4 & \text { ABG75998 } & 110559485 \\ \text { CvGal2 } & 4 & & \\ & & & \\ \text { CgGal1 (gal-1) } & 4 & \text { EKC37204 } & 405972434 \\ \text { CgGal2 (gal-2) } 4 & \text { EKC31760 } & 405966481 \\ \text { gal2 (4rth CRD only) } & \text { BAF75419 } & 154937048 \\ \text { CgGal9 } \quad 2 & \text { EKC40501 } & 405975976 \\ \text { CgGal } & 1^{2} & \text { EKC40502 } & 405975977\end{array}$

[55-59]

[60]

Crassostrea gigas

(Pacific oyster)

Ostrea edulis

OeGal

2

ADF80416

295136551

(Flat oyster)

\section{Pinctada fucata}

(Pearl oyster)

PoGal

PoGal2

\section{4}

ACO36044

225906399

$[67,68]$

Argopecten irradians

(Bay scallop)

AiGal-1

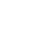

ADU60337

316936680

AiGal-2

4

ACS72240

241913784

$[64,65]$

Ruditapes philippinarum (Manila clam)

MCGal

2

ACS72241

241913786

ACA09732

167888935

$[66,70]$

Tegillarca granosa

(Blood clam)

Tg-GAL

2

AGH06131

460002040

[71]

Solen grandis

(Grand razor shell clam)

SgGal-1

2

AEW43449

363902082

[63]

\section{Gastropoda (Snails)}

\begin{tabular}{|c|c|c|c|c|c|}
\hline $\begin{array}{l}\text { Biomphalaria glabrata } \\
\text { (Freshwater snail) }\end{array}$ & $\begin{array}{l}\text { BgGal } \\
\text { BgGal4 } \\
\text { GREP }\end{array}$ & $\begin{array}{l}2 \\
4 \\
1\end{array}$ & $\begin{array}{l}\text { ABQ09359 } \\
\text { Locus } 2016(\mathrm{t}\end{array}$ & $\begin{array}{r}146199199 \\
\text { inscriptome) }\end{array}$ & $\begin{array}{l}{[62]} \\
{[107]} \\
{[72]}\end{array}$ \\
\hline $\begin{array}{l}\text { Haliotis rufescens } \\
\text { (Red abalone) }\end{array}$ & $\mathrm{HrGal}$ & 4 & AHX26603 & 613475854 & [69] \\
\hline $\begin{array}{l}\text { Haliotis discus hannai } \\
\text { (Disk abalone) }\end{array}$ & Hdh4 & 4 & ABN54798 & 125743200 & \\
\hline $\begin{array}{l}\text { Reishia clavigera } \\
\text { (Murex snail) }\end{array}$ & RcGal & $4^{3}$ & AET43927 & 356983730 & \\
\hline $\begin{array}{l}\text { Littorina littorea } \\
\text { (Periwinkle) }\end{array}$ & $\begin{array}{l}\text { LlGal1 } \\
\text { LlGal2 } \\
\text { LlGal3 }\end{array}$ & $\begin{array}{l}2 \\
2 \\
4\end{array}$ & $\begin{array}{l}\text { AJA37890 } \\
\text { AJA37869.1 } \\
\text { AJA37899 }\end{array}$ & $\begin{array}{l}735659649 \\
735659607 \\
735659667\end{array}$ & [106] \\
\hline
\end{tabular}


${ }^{1}$ If no reference is indicated, the sequence source is GeneBank or a similar genomic or transcriptomic database

${ }^{2}$ Yamaura K, Takahashi KG, Suzuki T. Comp Biochem Physiol B Biochem Mol Biol 2008;149:168e75 (This sequence appears to be a single domain of the 2-CRD species CgGal9, EKC40501)

${ }^{3}$ Partial sequence. 


\section{References}

1. Laine RA. The information-storing potential of the sugar code, in Glycosciences: status and perspectives (Gabius, H-J \& Gabius, S, eds). 1997 pp. 5-14:Chapman \& Hill, Weinheim. 2. Bakkers J, Semino CE, Stroband H, Kijne JW, Robbins PW, Spaink HP. An important developmental role for oligosaccharides during early embryogenesis of cyprinid fish. Proceedings of the National Academy of Sciences of the United States of America. 1997 94:7982-6.

3. Hathaway HJ, Shur BD. Transgenic approaches to glycobiology. Glycosciences: status and perspectives (Gabius, H-J \& Gabius, S, eds). 1997:pp. 507-17.

4. Cooper DNW. Galectinomics: finding themes in complexity. Biochimica et biophysica acta. 2002 1572:209-31.

5. Vasta GR, Quesenberry M, Ahmed H, O'Leary N. C-type lectins and galectins mediate innate and adaptive immune functions: their roles in the complement activation pathway. Dev Comp Immunol. 1999 23:401-20.

6. Walser PJ, Haebel PW, Kunzler M, Sargent D, Kues U, Aebi M, et al. Structure and functional analysis of the fungal galectin CGL2. Structure. 2004 12:689-702.

7. Stalz H, Roth U, Schleuder D, Macht M, Haebel S, Strupat K, et al. The Geodia cydonium galectin exhibits prototype and chimera-type characteristics and a unique sequence polymorphism within its carbohydrate recognition domain. Glycobiology. 2006 16:402-14.

8. Saouros S, Edwards-Jones B, Reiss M, Sawmynaden K, Cota E, Simpson P, et al. A novel galectin-like domain from Toxoplasma gondii micronemal protein 1 assists the folding, assembly, and transport of a cell adhesion complex. The Journal of biological chemistry. 2005 280:38583-91.

9. Hirabayashi J, Kasai K. The family of metazoan metal-independent beta-galactosidebinding lectins: structure, function and molecular evolution. Glycobiology. 1993 3:297-304.

10. Cherayil BJ, Weiner SJ, Pillai S. The Mac-2 antigen is a galactose-specific lectin that binds IgE. The Journal of experimental medicine. 1989 170:1959-72.

11. Cooper DN, Barondes SH. Evidence for export of a muscle lectin from cytosol to extracellular matrix and for a novel secretory mechanism. The Journal of cell biology. 1990 110:1681-91.

12. Cho M, Cummings RD. Galectin-1, a beta-galactoside-binding lectin in Chinese hamster ovary cells. II. Localization and biosynthesis. The Journal of biological chemistry. 1995 270:5207-12.

13. Sato S, Hughes RC. Regulation of secretion and surface expression of Mac-2, a galactoside-binding protein of macrophages. The Journal of biological chemistry. 1994 269:4424-30.

14. Cleves AE, Cooper DN, Barondes SH, Kelly RB. A new pathway for protein export in Saccharomyces cerevisiae. The Journal of cell biology. 1996 133:1017-26.

15. Rabinovich GA, Toscano MA, Jackson SS, Vasta GR. Functions of cell surface galectinglycoprotein lattices. Current opinion in structural biology. 2007 17:513-20.

16. Skrincosky DM, Allen HJ, Bernacki RJ. Galaptin-mediated adhesion of human ovarian carcinoma A121 cells and detection of cellular galaptin-binding glycoproteins. Cancer research. 1993 53:2667-75. 
17. Parsons MJ, Pollard SM, Saude L, Feldman B, Coutinho P, Hirst EMA, et al. Zebrafish mutants identify an essential role for laminins in notochord formation. Development. 2002 129:3137-46.

18. Fang R, Mantle M, Ceri H. Characterization of quail intestinal mucin as a ligand for endogenous quail lectin. The Biochemical journal. 1993293 ( Pt 3):867-72.

19. Ozeki Y, Matsui T, Yamamoto Y, Funahashi M, Hamako J, Titani K. Tissue fibronectin is an endogenous ligand for galectin-1. Glycobiology. 1995 5:255-61.

20. Mey A, Leffler H, Hmama Z, Normier G, Revillard JP. The animal lectin galectin-3 interacts with bacterial lipopolysaccharides via two independent sites. J Immunol. 1996 156:1572-7.

21. Sato S, Ouellet N, Pelletier I, Simard M, Rancourt A, Bergeron MG. Role of galectin-3 as an adhesion molecule for neutrophil extravasation during streptococcal pneumonia. J Immunol. 2002 168:1813-22.

22. John CM, Jarvis GA, Swanson KV, Leffler H, Cooper MD, Huflejt ME, et al. Galectin-3 binds lactosaminylated lipooligosaccharides from Neisseria gonorrhoeae and is selectively expressed by mucosal epithelial cells that are infected. Cell Microbiol. 2002 4:649-62.

23. Altman E, Harrison BA, Latta RK, Lee KK, Kelly JF, Thibault P. Galectin-3-mediated adherence of Proteus mirabilis to Madin-Darby canine kidney cells. Biochem Cell Biol. 2001 79:783-8.

24. Beatty WL, Rhoades ER, Hsu DK, Liu F-T, Russell DG. Association of a macrophage galactoside-binding protein with Mycobacterium-containing phagosomes. Cell Microbiol. 2002 4:167-76.

25. Gupta SK, Masinick S, Garrett M, Hazlett LD. Pseudomonas aeruginosa lipopolysaccharide binds galectin-3 and other human corneal epithelial proteins. Infection and immunity. 1997 65:2747-53.

26. Pelletier I, Hashidate T, Urashima T, Nishi N, Nakamura T, Futai M, et al. Specific recognition of Leishmania major poly-beta-galactosyl epitopes by galectin-9: possible implication of galectin-9 in interaction between L. major and host cells. The Journal of biological chemistry. 2003 278:22223-30.

27. Vasta GR. Roles of galectins in infection. Nature reviews Microbiology. 2009 7:424-38.

28. Barondes SH, Cooper DN, Gitt MA, Leffler H. Galectins. Structure and function of a large family of animal lectins. The Journal of biological chemistry. 1994 269:20807-10.

29. Liu FT. Galectins: a new family of regulators of inflammation. Clin Immunol. 2000 97:79-88.

30. Ahmed H, Pohl J, Fink NE, Strobel F, Vasta GR. The primary structure and carbohydrate specificity of a beta-galactosyl-binding lectin from toad (Bufo arenarum Hensel) ovary reveal closer similarities to the mammalian galectin-1 than to the galectin from the clawed frog Xenopus laevis. The Journal of biological chemistry. 1996 271:33083-94.

31. Ahmed H, Du S-J, O'Leary N, Vasta GR. Biochemical and molecular characterization of galectins from zebrafish (Danio rerio): notochord-specific expression of a prototype galectin during early embryogenesis. Glycobiology. 2004 14:219-32.

32. Shoji H, Deltour L, Nakamura T, Tajbakhsh S, Poirier F. Expression pattern and role of Galectin1 during early mouse myogenesis. Dev Growth Differ. 2009 51:607-15.

33. Vasta GR, Ahmed H, Amzel LM, Bianchet MA. Galectins from amphibian species: Carbohydrate specificity, molecular structure, and evolution. Trends Glycosci Glycotechnol. 1997 9:131-44. 
34. Ogden AT, Nunes I, Ko K, Wu S, Hines CS, Wang AF, et al. GRIFIN, a novel lensspecific protein related to the galectin family. The Journal of biological chemistry. 1998 273:28889-96.

35. Ahmed H, Vasta GR. Unlike mammalian GRIFIN, the zebrafish homologue (DrGRIFIN) represents a functional carbohydrate-binding galectin. Biochemical and biophysical research communications. 2008 371:350-5.

36. Di Lella S, Sundblad V, Cerliani JP, Guardia CM, Estrin DA, Vasta GR, et al. When galectins recognize glycans: from biochemistry to physiology and back again. Biochemistry. 2011 50:7842-57.

37. Vasta GR, Ahmed H. Animal Lectins: A Functional View: CRC Press; 2008.

38. Colnot C, Ripoche MA, Scaerou F, Foulis D, Poirier F. Galectins in mouse embryogenesis. Biochemical Society transactions. 1996 24:141-6.

39. Colnot C, Sidhu SS, Balmain N, Poirier F. Uncoupling of chondrocyte death and vascular invasion in mouse galectin 3 null mutant bones. Developmental biology. 2001 229:203-14.

40. Fukumori T, Kanayama H-O, Raz A. The role of galectin-3 in cancer drug resistance. Drug Resist Updat. 2007 10:101-8.

41. Guha P, Kaptan E, Bandyopadhyaya G, Kaczanowska S, Davila E, Thompson K, et al. Cod glycopeptide with picomolar affinity to galectin-3 suppresses T-cell apoptosis and prostate cancer metastasis. Proceedings of the National Academy of Sciences of the United States of America. 2013 110:5052-7.

42. Croci DO, Cerliani JP, Dalotto-Moreno T, Mendez-Huergo SP, Mascanfroni ID, DerganDylon $\mathrm{S}$, et al. Glycosylation-dependent lectin-receptor interactions preserve angiogenesis in anti-VEGF refractory tumors. Cell. 2014 156:744-58.

43. Vasta GR, Ahmed H, Nita-Lazar M, Banerjee A, Pasek M, Shridhar S, et al. Galectins as self/non-self recognition receptors in innate and adaptive immunity: an unresolved paradox. Frontiers in immunology. 2012 3:199.

44. Colnot C, Ripoche M, Fowlis D, Cannon V, Scaerou F, Cooper DNW, et al. The role of galectins in mouse development. Trends Glycosci Glycotechnol. 1997 9:31-40.

45. Vasta GR, Ahmed H, Du S, Henrikson D. Galectins in teleost fish: Zebrafish (Danio rerio) as a model species to address their biological roles in development and innate immunity. Glycoconj J. 2004 21:503-21.

46. Perillo NL, Pace KE, Seilhamer JJ, Baum LG. Apoptosis of T cells mediated by galectin1. Nature. 1995 378:736-9.

47. Hernandez JD, Baum LG. Ah, sweet mystery of death! Galectins and control of cell fate. Glycobiology. 2002 12:127R-36R.

48. Liu F-T, Rabinovich GA. Galectins as modulators of tumour progression. Nature reviews Cancer. 2005 5:29-41.

49. Raz A, Zhu DG, Hogan V, Shah N, Raz T, Karkash R, et al. Evidence for the role of 34$\mathrm{kDa}$ galactoside-binding lectin in transformation and metastasis. International journal of cancer Journal international du cancer. 1990 46:871-7.

50. Rabinovich GA, Rubinstein N, Toscano MA. Role of galectins in inflammatory and immunomodulatory processes. Biochimica et biophysica acta. 2002 1572:274-84.

51. Garred P, Larsen F, Seyfarth J, Fujita R, Madsen HO. Mannose-binding lectin and its genetic variants. Genes and immunity. 2006 7:85-94.

52. Casadevall A, Pirofski LA. Host-pathogen interactions: basic concepts of microbial commensalism, colonization, infection, and disease. Infection and immunity. 2000 68:6511-8. 
53. Lackie AM. Immune mechanisms in insects. Parasitol Today. 1988 4:98-9105.

54. Baum LG, Garner OB, Schaefer K, Lee B. Microbe-Host Interactions are Positively and Negatively Regulated by Galectin-Glycan Interactions. Frontiers in immunology. 2014 5:284. 55. Vasta GR, Sullivan JT, Cheng TC, Marchalonis JJ, Warr GW. A cell membraneassociated lectin of the oyster hemocyte. Journal of Invertebrate Pathology. 1982 40:367-77. 56. Vasta GR, Cheng TC, Marchalonis JJ. A lectin on the hemocyte membrane of the oyster (Crassostrea virginica). Cellular immunology. 1984 88:475-88.

57. Tasumi S, Vasta GR. A galectin of unique domain organization from hemocytes of the Eastern oyster (Crassostrea virginica) is a receptor for the protistan parasite Perkinsus marinus. J Immunol. 2007 179:3086-98.

58. Feng C, Ghosh A, Amin MN, Giomarelli B, Shridhar S, Banerjee A, et al. The galectin $\mathrm{CvGal1}$ from the eastern oyster (Crassostrea virginica) binds to blood group A oligosaccharides on the hemocyte surface. The Journal of biological chemistry. 2013 288:24394-409.

59. Kurz S, Jin C, Hykollari A, Gregorich D, Giomarelli B, Vasta GR, et al. Hemocytes and plasma of the eastern oyster (Crassostrea virginica) display a diverse repertoire of sulfated and blood group A-modified N-glycans. The Journal of biological chemistry. 2013 288:24410-28. 60. Feng C, Ghosh A, Amin MN, Bachvaroff TR, Tasumi S, Pasek M, et al. The Galectin $\mathrm{CvGa} 2$ from the eastern oyster (Crassostrea virginica) displays unique specificity for $\mathrm{ABH}$ blood group oligosaccharides and differentially recognizes sympatric Perkinsus species. The Journal of biological chemistry. 2015 (Submitted).

61. Yamaura K, Takahashi KG, Suzuki T. Identification and tissue expression analysis of Ctype lectin and galectin in the Pacific oyster, Crassostrea gigas. Comparative biochemistry and physiology Part B, Biochemistry \& molecular biology. 2008 149:168-75.

62. Yoshino TP, Dinguirard N, Kunert J, Hokke CH. Molecular and functional characterization of a tandem-repeat galectin from the freshwater snail Biomphalaria glabrata, intermediate host of the human blood fluke Schistosoma mansoni. Gene. 2008 411:46-58. 63. Wei X, Yang J, Liu X, Yang D, Xu J, Fang J, et al. Identification and transcriptional analysis of two types of lectins (SgCTL-1 and SgGal-1) from mollusk Solen grandis. Fish \& shellfish immunology. 2012 33:204-12.

64. Song X, Zhang H, Wang L, Zhao J, Mu C, Song L, et al. A galectin with quadrupledomain from bay scallop Argopecten irradians is involved in innate immune response. Dev Comp Immunol. 2011 35:592-602.

65. Song X, Zhang H, Zhao J, Wang L, Qiu L, Mu C, et al. An immune responsive multidomain galectin from bay scallop Argopectens irradians. Fish \& shellfish immunology. 2010 28:326-32.

66. Kim JY, Kim YM, Cho SK, Choi KS, Cho M. Noble tandem-repeat galectin of Manila clam Ruditapes philippinarum is induced upon infection with the protozoan parasite Perkinsus olseni. Dev Comp Immunol. 2008 32:1131-41.

67. Zhang DC, Hu YT, Guo HY, Cui SG, Su TF, Jiang SG. cDNA cloning and mRNA expression of a tandem-repeat galectin (PoGal2) from the pearl oyster, Pinctada fucata. Genetics and molecular research : GMR. 2011 10:1963-74.

68. Zhang D, Jiang S, Hu Y, Cui S, Guo H, Wu K, et al. A multidomain galectin involved in innate immune response of pearl oyster Pinctada fucata. Dev Comp Immunol. 2011 35:1-6.

69. Maldonado-Aguayo W, Teneb J, Gallardo-Escarate C. A galectin with quadruple-domain from red abalone Haliotis rufescens involved in the immune innate response against to Vibrio anguillarum. Fish \& shellfish immunology. 2014 40:1-8. 
70. Jeffroy F, Brulle F, Paillard C. Differential expression of genes involved in immunity and biomineralization during Brown Ring Disease development and shell repair in the Manila clam, Ruditapes philippinarum. J Invertebr Pathol. 2013 113:129-36.

71. Bao Y, Shen H, Zhou H, Dong Y, Lin Z. A tandem-repeat galectin from blood clam Tegillarca granosa and its induced mRNA expression response against bacterial challenge. Genes Genom. 2013 35:733-40.

72. Dheilly NM, Duval D, Mouahid G, Emans R, Allienne JF, Galinier R, et al. A family of variable immunoglobulin and lectin domain containing molecules in the snail Biomphalaria glabrata. Dev Comp Immunol. 2015 48:234-43.

73. Arata Y, Hirabayashi J, Kasai Ki. Structure of the 32-kDa galectin gene of the nematode Caenorhabditis elegans. The Journal of biological chemistry. 1997 272:26669-77.

74. Ahmed H, Bianchet MA, Amzel LM, Hirabayashi J, Kasai K-I, Giga-Hama Y, et al. Novel carbohydrate specificity of the 16-kDa galectin from Caenorhabditis elegans: binding to blood group precursor oligosaccharides (type 1, type 2, Talpha, and Tbeta) and gangliosides. Glycobiology. 2002 12:451-61.

75. Chiariotti L, Wells V, Bruni CB, Mallucci L. Structure and expression of the negative growth factor mouse beta-galactoside binding protein gene. Biochimica et biophysica acta. 1991 1089:54-60.

76. Gitt MA, Barondes SH. Genomic sequence and organization of two members of a human lectin gene family. Biochemistry. 1991 30:82-9.

77. Bianchet MA, Ahmed H, Vasta GR, Amzel LM. Soluble beta-galactosyl-binding lectin (galectin) from toad ovary: crystallographic studies of two protein-sugar complexes. Proteins. 2000 40:378-88.

78. Boehm T. Evolution of vertebrate immunity. Current biology : CB. 2012 22:R722-32.

79. Bachere E, Gueguen Y, Gonzalez M, de Lorgeril J, Garnier J, Romestand B. Insights into the anti-microbial defense of marine invertebrates: the penaeid shrimps and the oyster Crassostrea gigas. Immunological reviews. 2004 198:149-68.

80. Rafferty GP, Powell R. Identification of genes expressed in the gill tissue of the Pacific oyster (Crassostrea gigas) using expressed-sequence tags. J Molluscan Stud. 2002 68:397.

81. Gueguen Y, Cadoret JP, Flament D, Barreau-Roumiguiere C, Girardot AL, Garnier J, et al. Immune gene discovery by expressed sequence tags generated from hemocytes of the bacteria-challenged oyster, Crassostrea gigas. Gene. 2003 303:139-45.

82. Jomori T, Natori S. Function of the lipopolysaccharide-binding protein of Periplaneta americana as an opsonin. FEBS letters. 1992 296:283-6.

83. Levashina EA, Moita LF, Blandin S, Vriend G, Lagueux M, Kafatos FC. Conserved role of a complement-like protein in phagocytosis revealed by dsRNA knockout in cultured cells of the mosquito, Anopheles gambiae. Cell. 2001 104:709-18.

84. Ramet M, Manfruelli P, Pearson A, Mathey-Prevot B, Ezekowitz RA. Functional genomic analysis of phagocytosis and identification of a Drosophila receptor for E. coli. Nature. 2002 416:644-8.

85. Terahara K, Takahashi KG, Nakamura A, Osada M, Yoda M, Hiroi T, et al. Differences in integrin-dependent phagocytosis among three hemocyte subpopulations of the Pacific oyster "Crassostrea gigas". Dev Comp Immunol. 2006 30:667-83.

86. Yu XQ, Kanost MR. Immulectin-2, a lipopolysaccharide-specific lectin from an insect, Manduca sexta, is induced in response to gram-negative bacteria. The Journal of biological chemistry. 2000 275:37373-81. 
87. Wang X, Rocheleau TA, Fuchs JF, Hillyer JF, Chen CC, Christensen BM. A novel lectin with a fibrinogen-like domain and its potential involvement in the innate immune response of Armigeres subalbatus against bacteria. Insect Mol Biol. 2004 13:273-82.

88. Davicino RC, Elicabe RJ, Di Genaro MS, Rabinovich GA. Coupling pathogen recognition to innate immunity through glycan-dependent mechanisms. Int Immunopharmacol. 2011 11:1457-63.

89. Holmskov U, Thiel S, Jensenius JC. Collections and ficolins: humoral lectins of the innate immune defense. Annu Rev Immunol. 2003 21:547-78.

90. Vasta GR, Ahmed H, Bianchet MA, Fernandez-Robledo JA, Amzel LM. Diversity in recognition of glycans by F-type lectins and galectins: molecular, structural, and biophysical aspects. Ann N Y Acad Sci. 2012 1253:14-26.

91. Stowell SR, Arthur CM, Dias-Baruffi M, Rodrigues LC, Gourdine J-P, HeimburgMolinaro J, et al. Innate immune lectins kill bacteria expressing blood group antigen. Nature medicine. 2010 16:295-301.

92. Toledo KA, Fermino ML, Andrade Cdel C, Riul TB, Alves RT, Muller VD, et al. Galectin-1 Exerts Inhibitory Effects during DENV-1 Infection. PloS one. 2014 9:e112474.

93. Yang M-L, Chen Y-H, Wang S-W, Huang Y-J, Leu C-H, Yeh N-C, et al. Galectin-1 binds to influenza virus and ameliorates influenza virus pathogenesis. Journal of virology. 2011 85:10010-20.

94. Jing X, Espinosa EP, Perrigault M, Allam B. Identification, molecular characterization and expression analysis of a mucosal C-type lectin in the eastern oyster, Crassostrea virginica. Fish \& shellfish immunology. 2011 30:851-8.

95. Wright AC, Ahmed H, Gauthier JD, Silva AM, Vasta GR. cDNA cloning and characterization of two iron superoxide dismutases from the oyster parasite Perkinsus marinus. Mol Biochem Parasitol. 2002 123:73-7.

96. Schott EJ, Vasta GR. The PmSOD1 gene of the protistan parasite Perkinsus marinus complements the sod $2 \Delta$ mutant of Saccharomyces cerevisiae, and directs an iron superoxide dismutase to mitochondria. Mol Biochem Parasitol. 2003 126:81-92.

97. Schott EJ, Robledo JAF, Wright AC, Silva AM, Vasta GR. Gene organization and homology modeling of two iron superoxide dismutases of the early branching protist Perkinsus marinus. Gene. 2003 309:1-9.

98. Ahmed H, Schott EJ, Gauthier JD, Vasta GR. Superoxide dismutases from the oyster parasite Perkinsus marinus: purification, biochemical characterization, and development of a plate microassay for activity. Anal Biochem. 2003 318:132-41.

99. Schott EJ, Pecher WT, Okafor F, Vasta GR. The protistan parasite Perkinsus marinus is resistant to selected reactive oxygen species. Exp Parasitol. 2003 105:232-40.

100. Asojo OA, Schott EJ, Vasta GR, Silva AM. Structures of PmSOD1 and PmSOD2, two superoxide dismutases from the protozoan parasite Perkinsus marinus. Acta crystallographica Section F, Structural biology and crystallization communications. 2006 62:1072-5.

101. Alavi MR, Fernandez-Robledo JA, Vasta GR. Development of an in vitro assay to examine intracellular survival of Perkinsus marinus trophozoites upon phagocytosis by oyster (Crassostrea virginica and Crassostrea ariakensis) hemocytes. The Journal of parasitology. 2009 95:900-7.

102. Kamhawi S, Ramalho-Ortigao M, Pham VM, Kumar S, Lawyer PG, Turco SJ, et al. A role for insect galectins in parasite survival. Cell. 2004 119:329-41. 
103. Ouellet M, Mercier S, Pelletier I, Bounou S, Roy J, Hirabayashi J, et al. Galectin-1 acts as a soluble host factor that promotes HIV-1 infectivity through stabilization of virus attachment to host cells. J Immunol. 2005 174:4120-6.

104. Okumura CY, Baum LG, Johnson PJ. Galectin-1 on cervical epithelial cells is a receptor for the sexually transmitted human parasite Trichomonas vaginalis. Cell Microbiol. 2008 10:2078-90.

105. Bastida-Corcuera FD, Okumura CY, Colocoussi A, Johnson PJ. Trichomonas vaginalis lipophosphoglycan mutants have reduced adherence and cytotoxicity to human ectocervical cells. Eukaryot Cell. 2005 4:1951-8.

106. Gorbushin AM, Borisova EA. Lectin-like molecules in transcriptome of Littorina littorea hemocytes. Dev Comp Immunol. 2015 48:210-20.

107 Dheilly NM, Duval D, Mouahid G, Emans R, Allienne JF, Genthon C, Dubois E, Du Pasquier L, Adema C, Grunau C, Mitta G, and Gourbal B. De novo assembly of transcriptome from RNA-seq data as a tool to reveal the complexity of the snail Biomphalaria glabrata immune system. Release date: 2013 (http://2ei.univ-perp.fr/?page_id=89) 


\section{Figure legends}

\section{Figure 1: Domain organization of galectin types in vertebrates and aquatic mollusks. (A)}

Schematic representation of the domain organization of the three galectin types (proto, chimera, and tandem repeat) described in vertebrate species. (B) Schematic illustration of the domain organization in the two most prevalent galectin types (2-CRD and 4-CRD) described in aquatic mollusk species, and the two types described in single reports [1-CRD from C. gigas (61) and GREP from B. glabrata (72)]. GREP is a chimeric protein in which a C-terminal galectin domain (GLECT) is joined via a short interceding region (ICR) to two immunoglobulin superfamily domains (IgSF1 and IgSF2) separated by a small connecting region (SCR), and with the signal peptide (SP). The sequence of the 1-CRD galectin from the Pacific oyster $C$. gigas (the only single CRD galectin reported so far in aquatic mollusks) appears to be a single domain of the 2CRD galectin CgGal9 (EKC40501).

Figure 2: Glycan array analysis of CvGal1 specificity. Recombinant CvGal1 was subjected to glycan array analysis (Consortium for Functional Glycomics). The fluorescent signals along the glycan array are shown with the top-ranked signals labeled (top panel), and rearranged by signal strength as high to low from left to right (bottom panel). The eleven best ranked glycan CvGal 1 ligands are shown with their core structures boxed (middle panel).

Figure 3: Recognition of blood group A type 2 oligosaccharides by CvGal1. (A) The A2 blood antigen docked at the binding pocket of the CvGall model of the first CRD (N-CRD), using the observed common $\mathrm{N}$-Acetyllactosamine disaccharide bound to the template. CvGal1 binding site is shown as semi-transparent solvent accessible surface colored by its vacuum electrostatic potential (positive in blue to negative in red). The cartoon model of the protein is visible across the surface showing the interacting residues in a stick representation. H-bonds recognizing hydroxyl groups of the A2 antigen are displayed as dashed lines with their distances (in $\AA$ ) between heavy atoms indicated. (B) The model of the N-CRD of CvGall illustrated above in (A), is compared with the B, C and D CRDs to illustrated the differences in the topology of the binding pocket that reflect differences. 
Figure 4: Recognition of blood group oligosaccharides by galectins from $C$. virginica (CvGal1), R. clavigera, and B. glabrata. (A) The A2 blood oligosaccharide docked at the binding pocket of the CvGal1 model of the first CRD (N-CRD), is compared to the the N-CRD from the $B$. glabrata galectin BgGal and the binding site of the $R$. clavigera galectin. All three binding sites show the short loop 4 (indicated with the blue oval) that allows the accommodation of the fucosyl moiety of the A2 blood oligosaccharide. (B) The C-CRD of the B. glabrata galectin $\mathrm{BgGal}$ is compared to the galectin BaGal-1from the toad Bufo arenarum bound to $\mathrm{N}$ acetyllactosamine. Like the B. arenarum galectin, the snail galectin C-CRD exhibits the long loop 4 (indicated with the red oval) that hinders the binding of the A2 blood group oligosaccharide. These models reveal the structural basis for the expected differences in specificity of the B. glabrata $\mathrm{N}$ - and C-CRDs.

Figure 5. Phylogenetic analysis of 2- and 4-CRD galectins from aquatic mollusks. (A) A maximum likelhood phylogeny of full-length sequences of 2-CRD type galectins from aquatic mollusks (bivalves and gastropods). Bootstrap support (100 replicates) is shown above the branches when over 50\%. (B) A maximum likelhood phylogeny of individual domains from 2and 4-CRD galectins from bivalves and gastropods. The domain order is alphabetical from the $\mathrm{N}$-terminal CRD to the galectin C-terminus. Bootstrap support (100 replicates) is shown above the branches when over $50 \%$.

Figure 6. Schematic model of the proposed roles of a 4-CRD galectin in the uptake of microalgae, bacteria ,and protozoan parasites by hemocytes of an aquatic mollusk. (A) The 4-CRD galectin CvGal1 from the eastern oyster ( $C$. virginica) is secreted by the hemocytes and can cross-link the blood group oligosaccharide moieties on the hemocyte surface to glycans of similar topology on the surface of microalgae (Tetraselmis sp), bacteria, and the parasite $P$. marinus. (B) CvGal1-mediated recognition and cross-linking promotes phagocytosis by opsonic effect, and the microalgae and bacteria are killed in the hemocyte phagosome by reactive oxygen species produced during the respiratory burst. P. marinus escapes oxidative stress by expression of anti-oxidative enzymes (Superoxide dismutases, ascorbate-dependent peroxidases, etc). (C) $P$. marinus survives intracellular killing and proliferates within the hemocyte, eventually causing systemic infection and death of the oyster host. 
Fig. 1

A

Galectin types from vertebrates

Proto type

Chimera

Tandem-repeat
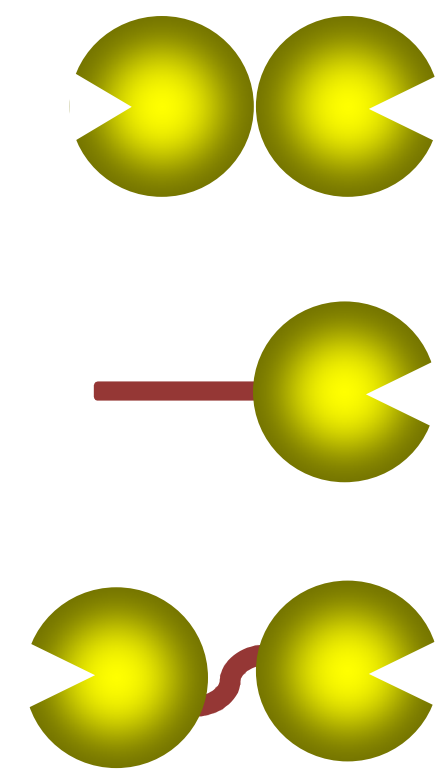

B

Galectin types from aquatic mollusks

1-CRD

2-CRD

4-CRD
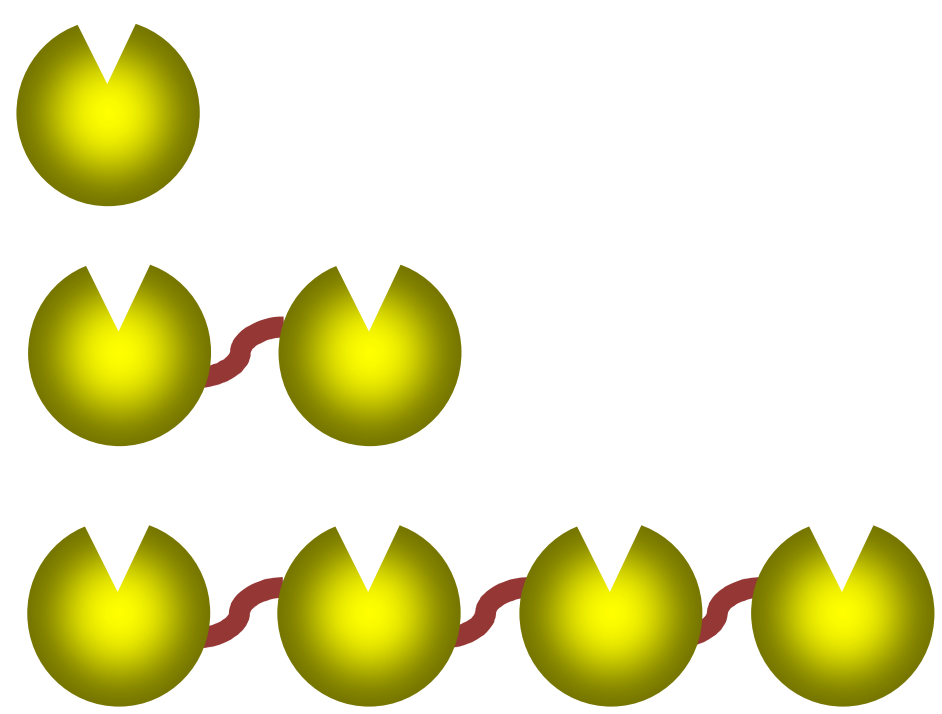

GREP

SP

IGSF1

SCR

IGSF2 

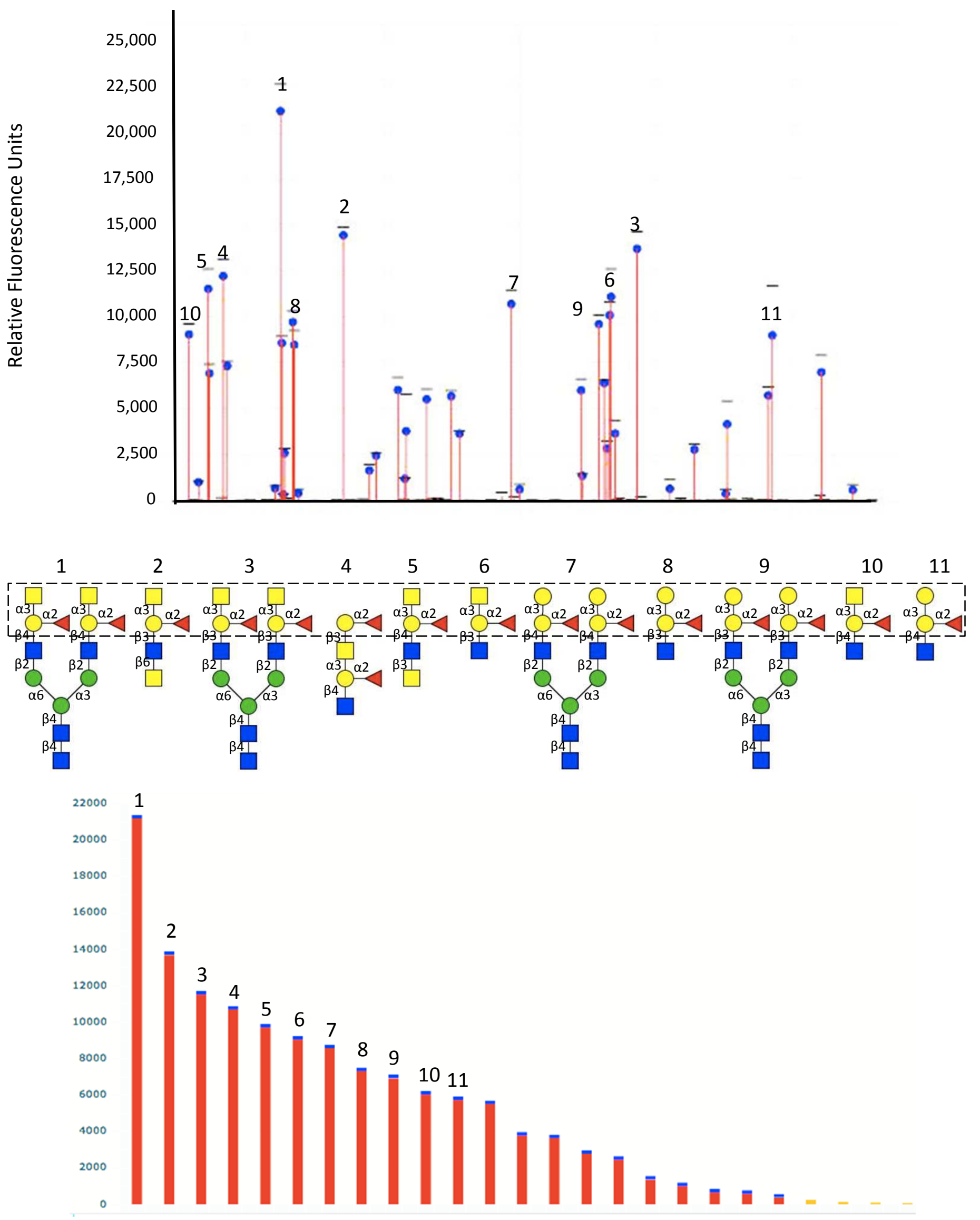


\section{Fig 3}

A

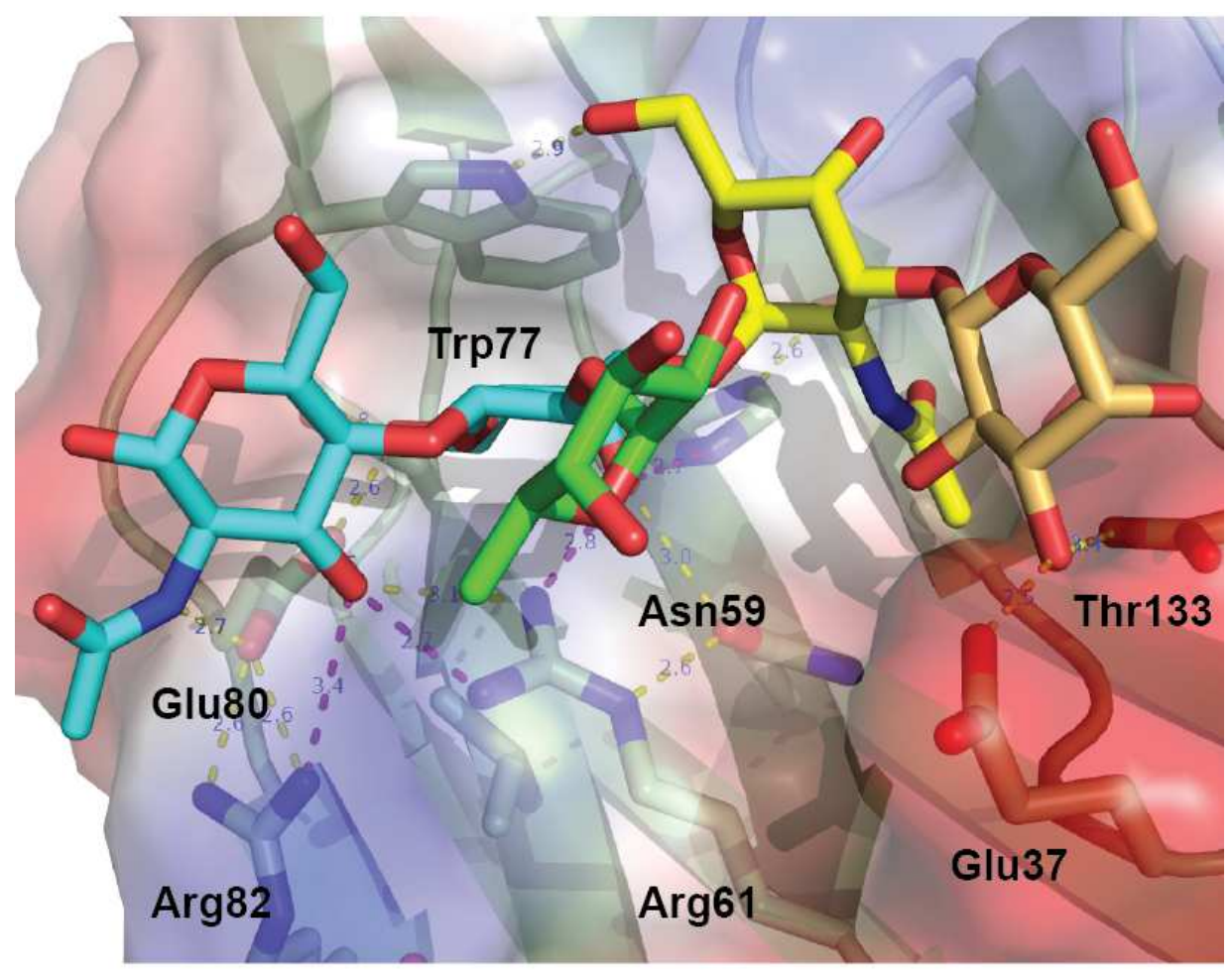

B
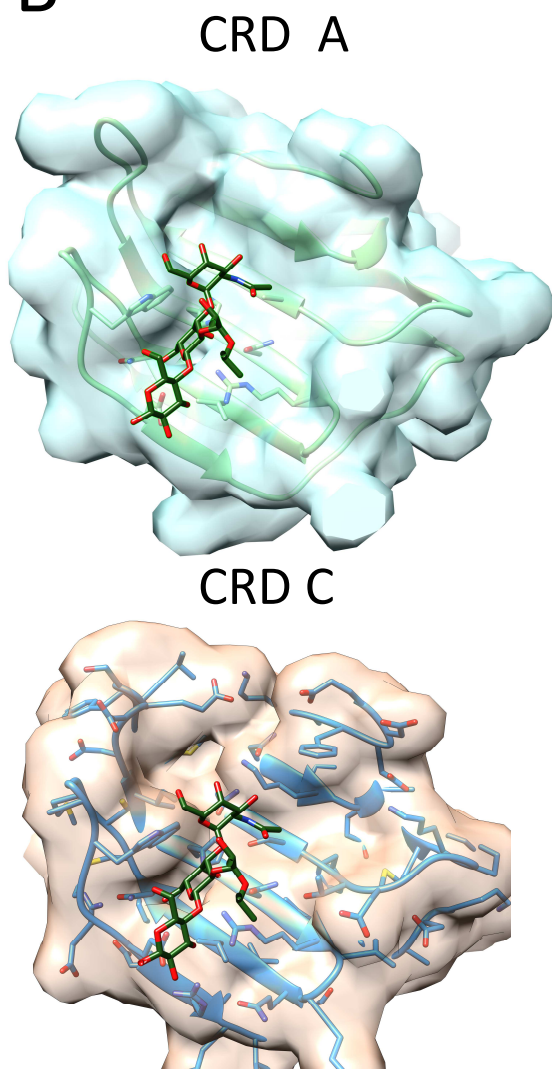

CRD B
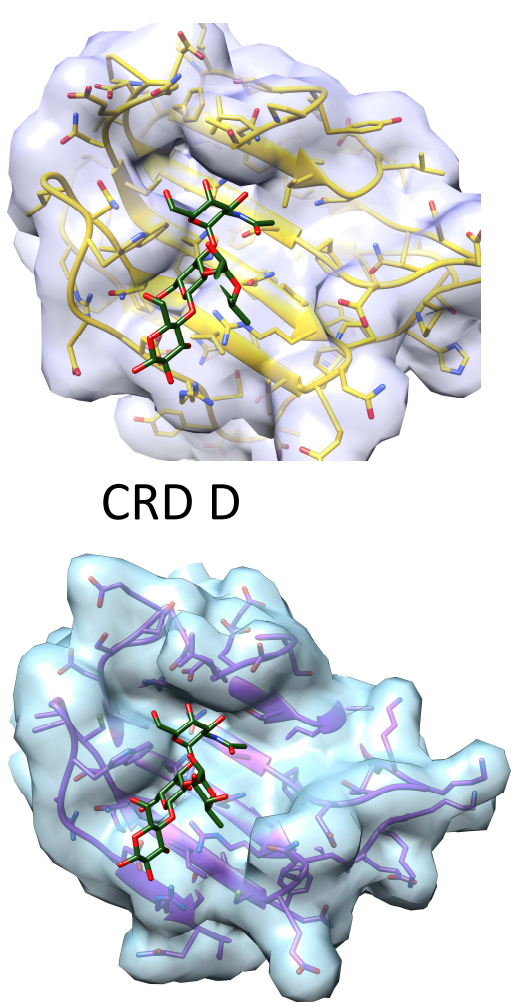


\section{Fig 4}

A

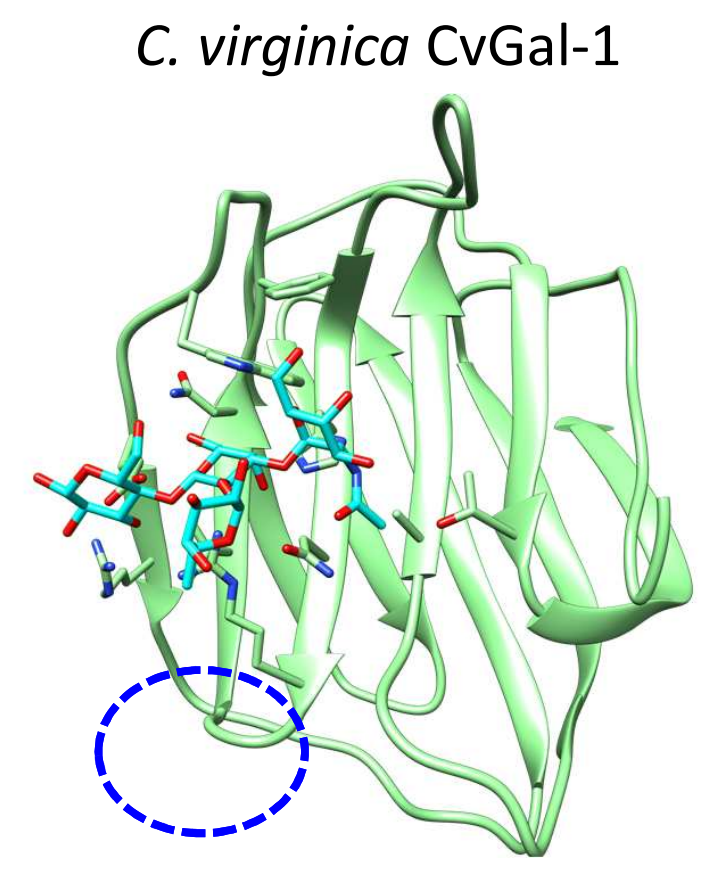

B. glabrata N-CRD

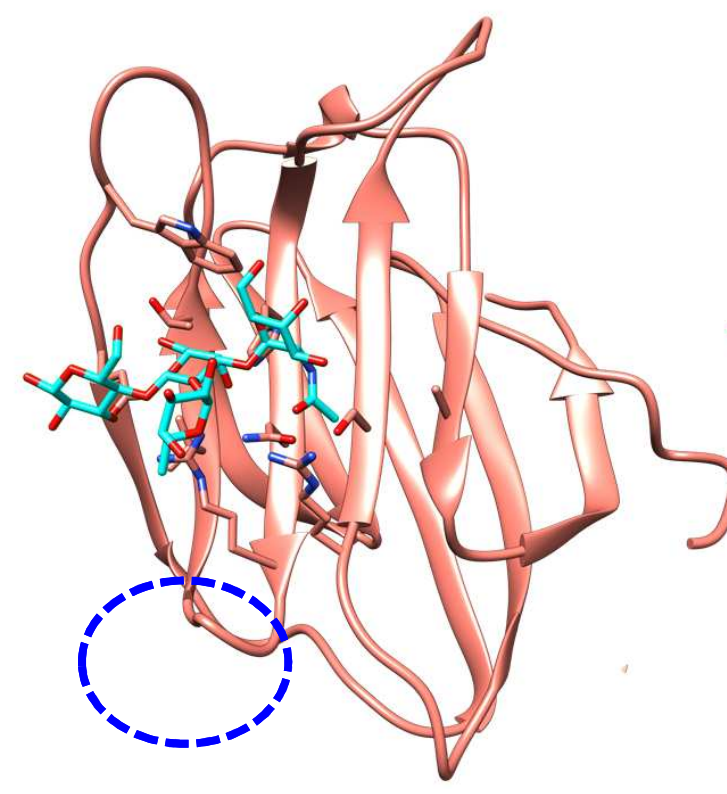

R. clavigera

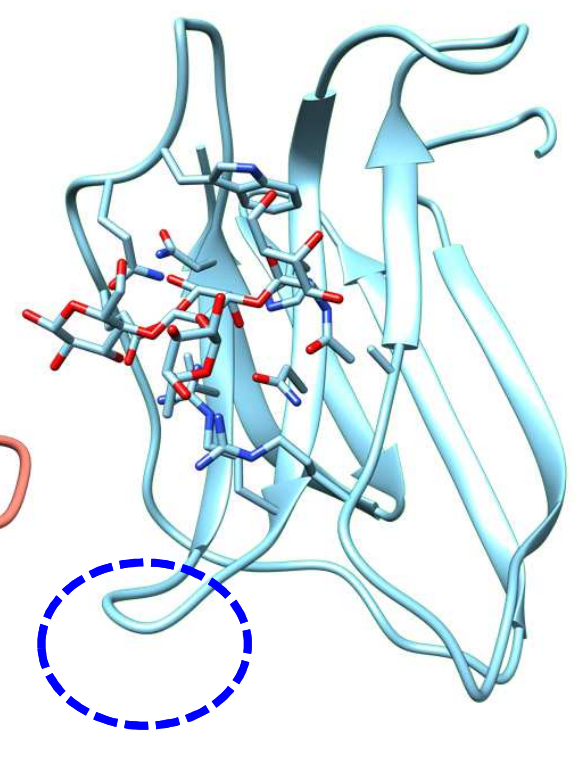


Fig 4

B

B. glabrata C-CRD

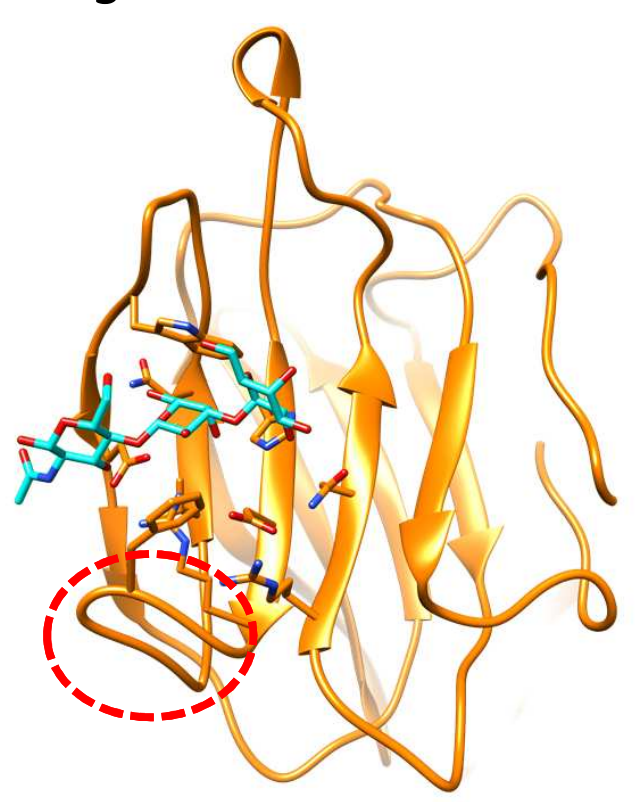

BaGal-1/Gal-GlcNAc

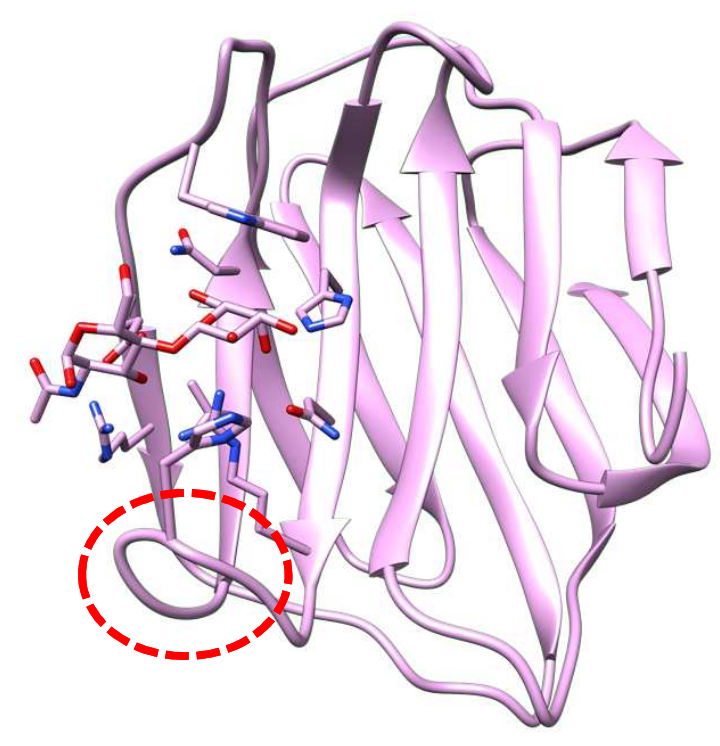




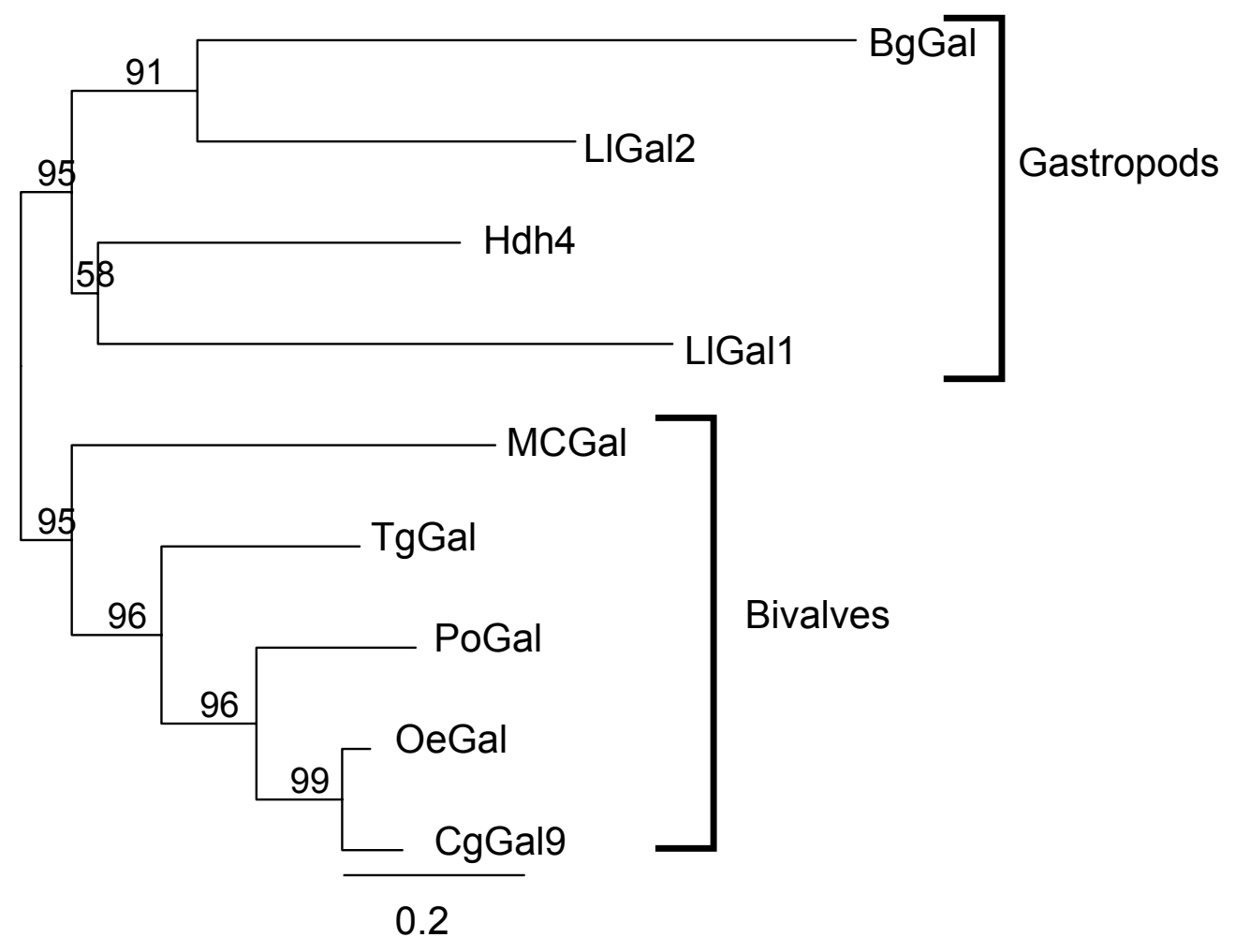




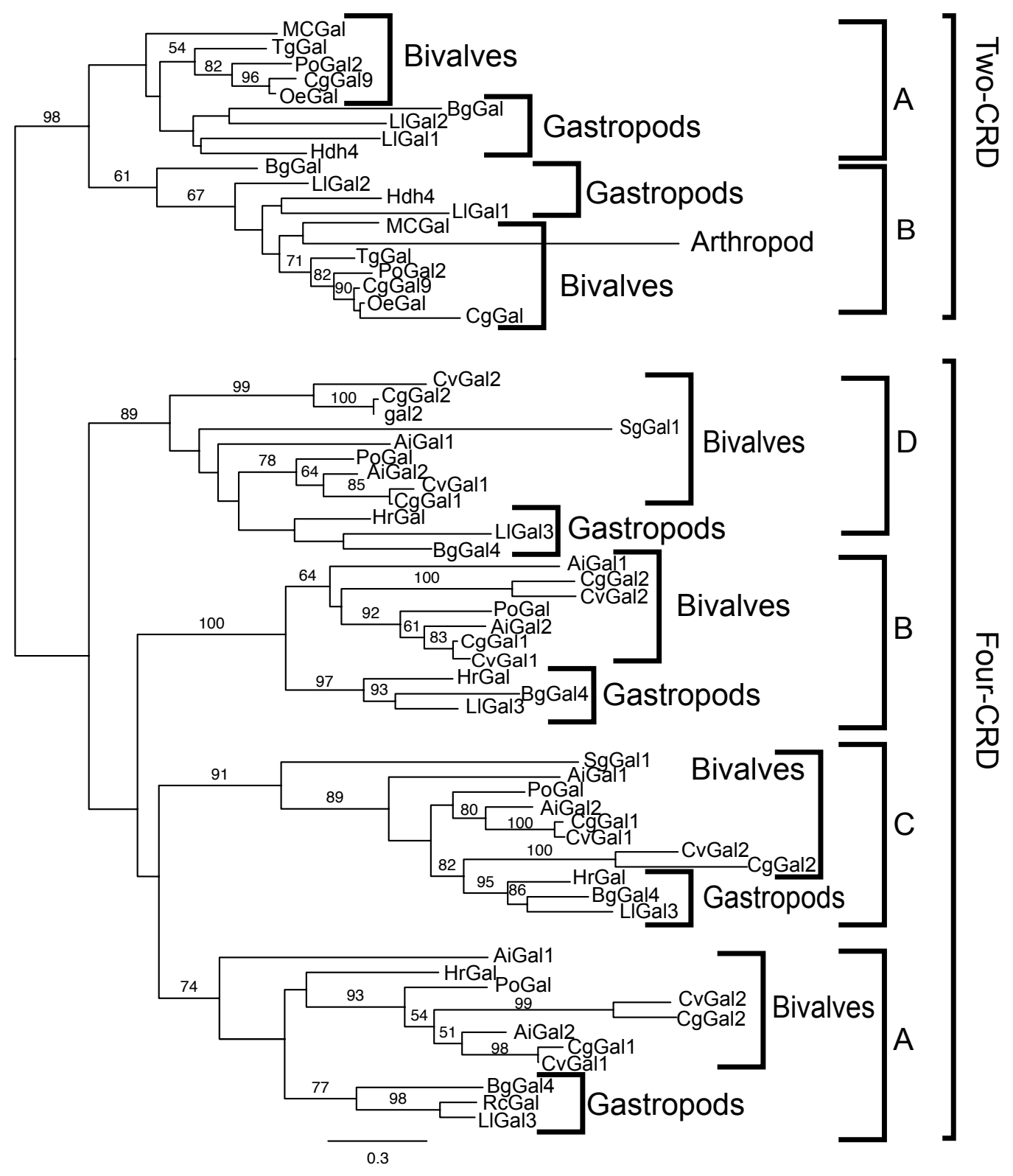




\section{Fig 6}

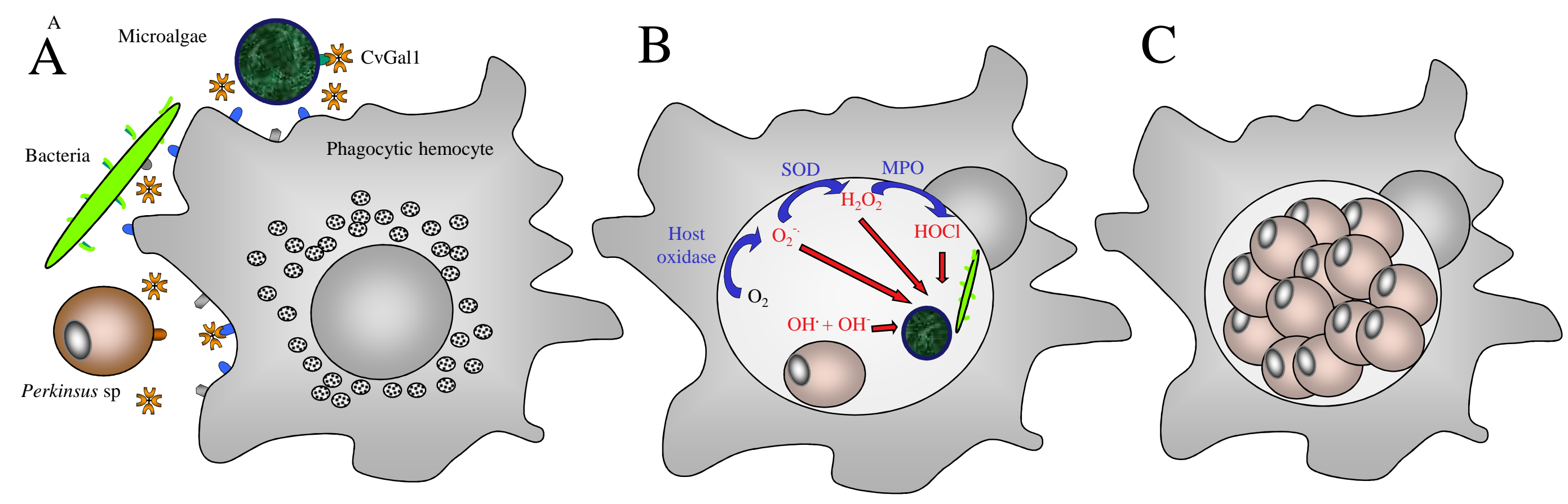


Discovery and characterization of galectins in mollusks has been relatively recent Galectin repertoires in mollusks are smaller and display unique domain organizations Galectins from mollusks may mediate uptake of microalgae for intracellular digestion Galectins promote phagocytosis of pathogens and parasites as a defense response Some protozoan parasites subvert the galectin's recognition functions for host entry 